\title{
NOTAS INORMACÖES
}

\section{CLASSIFICAÇÃO DAS PRÁTICAS DE ENFERMAGEM EM SAÚDE COLETIVA NO BRASIL}

Maria José Morais Antunes * Isília Aparecida Silva**

Emiko Yoshikawa Egry *** Roseni Rosângela Chompré ****

Em 1991, o Conselho Internacional de Enfermeiras (CIE) iniciou um processo no qual a questão central girava em torno do estabelecimento de um sistema de comunicação (local, regional e internacional), a partir de nomenclaturas específicas que dessem conta de descrever as mais distintas práticas da enfermagem no mundo. Desencadeou este processo, a constatação de que o trabalho da enfermagem, na enorme gama de ações construídas desde sua gênese - na moderna acepção - continua invisibilizada ainda, decorrente, entre outras causas, da inexistência de dados que expressem - no coletivo e no individual - claramente os Objetos de trabalho com os quais se defronta.

Albergando esta preocupação e sustentada na necessidade real de se apreender as distintas práticas de enfermagem em saúde coletiva no cenário brasileiro, a Associação Brasileira de Enfermagem, enquanto uma entidade profissional que tem "o compromisso ético, político e técnico de propor e defender políticas e programas que visem a melhoria da qualidade de vida da população..." (ABEn, 1994) constituiu, em 1996, o Projeto de Classificação das Práticas de Enfermagem em Saúde Coletiva no Brasil, cujos pressupostos e propósitos centrais serão a seguir descritos.

Consideradas a historicidade e a dinâmica das transformações no setor saúde, decorrentes das transformações sociais mais amplas (modo de produção da sociedade brasileira), o presente projeto tem como Objetivo Geral contribuir para a transformação das práticas de enfermagem em saúde coletiva no Brasil, tendo por referência os pressupostos da Reforma Sanitária Brasileira, os perfis de saúdedoença da população e a inscrição constitutiva da enfermagem no processo de produção de saúde.

$\mathrm{O}$ alcance deste objetivo hercúleo, para além da requerida estratégica operacional efetiva e do rigor metodológico, apoia-se na premissa de que todo o conhecimento verdadeiramente impactante no sentido de superação das contradições da prática deve existir e ser produzido num contexto de compartilha e reflexão conjunta do saber. Assim, o desenvolvimento do Projeto levará em conta tanto o processo quanto o produto, principalmente, no que se refere à qualificação e requalificação da força de trabalho em enfermagem, privilegiando-se neste caso o saber instrumental.

Os propósitos centrais do projeto são: A) estabelecer mecanismos de cooperação para a classificação da prática de enfermagem em saúde coletiva no País; B) revisitar as práticas de enfermagem em saúde coletiva no País, contextualizadas no processo

\footnotetext{
* Enfermeira. Mestre em Enfermagem pela UFMG. Doutoranda da EEUSP. Diretora de Assuntos Profissionais da ABEn, gestão 95/98. Coordenadora Geral do Projeto

** Enfermeira. Mestre em Enfermagem pela EEUSP. Doutora em Enfermagem pela EEUSP. Professor Doutor do Departamento de Enfermagem Materno-Infantil e Piquiátrica da EEUSP. Diretora do CEPEN (Centro de Estudos e Pesquisa em Enfermagem da ABEn), gestão 95/98. Coordenadora Geral Adjunta do Projeto

*** Enfermeira. Mestre em Enfermagem pela EEUSP. Doutora em Saúde Pública pela FSP-USP. Livre-Docente em Enfermagem em Saúde Coletiva pela EEUSP. Professora Titular em Enfermagem em Saúde Coletiva da EEUSP. Coordenadora Técnica do Projeto **** Enfermeira. Mestre em Veterinária (Área de Epidemiologia) pela UFMG. Doutora em Enfermagem pela EEUSP. Professora Adjunta da Escola de Enfermagem da UFMG. Consultora da Fundação W.K.Kellogg para a América Latina e Caribe. Coordenadora de Avaliação do Projeto
} 
de produção em saúde, diante da implantação do Sistema Único de Saúde; C) construir um sistema de informação das práticas de enfermagem em saúde coletiva que permita a sua classificação, troca de experiências e interlocução nos níveis nacional e internacional.

Subordinados a estes propósitos centrais, foram constituídos os objetivos específicos que se encontram descritos no Projeto.

O marco teórico-metodológico adotado configurou as categorias analíticas - momento investigativo - e as categorias interpretativas - momento interventivo - apresentando-se neste estudo, tal como se segue: trabalho (elementos constitutivos do processo de trabalho, formas de organização, infra-estrutura e recursos humanos); força de trabalho (composição, estruturação, organização, programas e estratégias de operacionalização e sistemas de qualificação e requalificação); educação (organização interna e articulação com as instituições de ensino e pesquisa); modelo assistencial (propostas teóricas de concretização e obstáculos para a implantação do SUS); enfermagem (teorias e marcos teóricos que embasam a prática, concretização da prática, obstáculos para a expansão das ações de enfermagem, parâmetros de avaliação da qualidade do trabalho e indicadores de avaliação e produção e reprodução de conhecimentos; e perfis epidemiológicos da população adscrita no Distrito Sanitário (processos de produção e reprodução social, indicadores demográficos, perfis de morbidade e mortalidade, mapeamento de grupos homogêneos).

O desenvolvimento do presente projeto contará com o apoio financeiro da Fundação W.K.Kellogg, assentado em base operativa das ABEns-seção, compartidas com a Academia e o Serviço, monitorados por supervisão regional (Núcleos A, B, C, D, E e F) e coordenados pela equipe de Coordenação Geral do Projeto, com cronograma inicial de três anos, de 1997 ao ano 2000.

\section{DOCENTES DO ENSINO MÉDIO DE ENFERMAGEM: O SIGNIFICADO ATRIBUÍDO À SUA} PRÁTICA PROFISSIONAL

Lúcia Helena Pereira dos Santos* Silvia Helena De Bortoli Cassiani **

Um grande contingente de trabalhadores de enfermagem constitui-se de profissionais de nível médio, ou seja, os técnicos e auxiliares de enfermagem. Há estimativas de que esses profissionais representam $60 \%$ da força de trabalho de enfermagem no Brasil (CONSELHO FEDERAL DE ENFERMAGEM, 1996). O interesse em trabalhar com o enfermeiro professor desses cursos é proveniente de conflitos e questionamentos referentes a essa prática; e ainda por considerar esse profissional como a peça fundamental para um ensino de qualidade. Este estudo de caráter compreensivista, prioriza o significado atribuído às coisas e a intencionalidade da ação, características que, segundo MINAYO (1992) são inerentes aos atos, às relações e às estruturas sociais. Trata-se portanto, de um estudo qualitativo, cujo objetivo é compreender o significado que os enfermeiros, docentes do ensino médio de enfermagem atribuem à sua prática profissional. Para a compreensão do fenômeno sob estudo, adotar-se-á o método da Teoria Fundamentada nos Dados, já que esta é uma forma de pesquisa de campo, que explora e descreve o fenômeno no ambiente em que ele se insere, constituindo-se assim, em uma teoria indutivamente derivada do fenômeno que representa.

* Enfermeira, Professora da Escola Técnica de Saúde da Universidade Federal de Uberlândia e Mestranda em Enfermagem Fundamental da Escola de Enfermagem de Ribeirão Preto da Universidade de São Paulo

** Enfermeira, Professora Doutora da Escola de Enfermagem de Ribeirão Preto da Universidade de São Paulo 